\title{
The Current Challenges in Sri Lanka's Rattan Manufacturing Industry
}

\author{
Rathnayaka, RMK'ㄹ, Kodithuwakku, $\mathbf{D}^{2}$ \\ ${ }^{1}$ Department of Geography, Faculty of Social Sciences, University of Kelaniya \\ ${ }^{2}$ Department of Social Statistics, Faculty of Social Sciences, University of Kelaniya \\ sandeeprathnayaka@gmail.com $^{1}$
}

\begin{abstract}
This research examines the contemporary challenges associated with the rattan manufacturing industry in Sri Lanka. Accordingly, the main objective of this research is to identify the current challenges associated with the rattan manufacturing industry. This research was carried out using a mixed methodology under the inductive approach. Quantitative and qualitative data were used for the research and they were collected from primary and secondary sources. The secondary data were collected through DSD offices, resource profiles, district, and statistical handbooks, relevant websites, and journal articles. Questionnaires, structured and semi-structured interviews, were used to obtain primary data. Radawadunna Grama Niladhari Division of the Mirigama Divisional Secretariat Division in the Gampaha District in Sri Lanka was selected as the sample for conducting this study. The reason for selecting this area for this study was that this area is identified as a place significantly famous for rattan-related products and trade. Ten attributes were derived from the literature survey to identify the research objective. A factor analysis was performed using SPSS software and the analyzed data were presented in tables. After analyzing data, it was identified the challenges faced by the traders engaged in the rattan manufacturing industry in this area. Thus, the four factors can be named as, Resource scarcity, Market factors, Spatial factors and, Cultural factors. Under these four main factors, several other sub-factors can be identified. Accordingly, the study finally identified several challenges associated with the rattan industry in present Sri Lanka.
\end{abstract}

Keywords - Rattan, Rattan production, Rattan manufacturing industry, Sri Lanka 


\section{Introduction}

This research paper associated with mainly the current challenges related to the rattan manufacturing industry in the Radawadunna Grama Niladhari Division of Sri Lanka. The rattan manufacturing industry belongs to the category of primary economic activities. The primary economic activities are located under the influence of labour, raw materials, markets, etc (Huang et al., 2019). The above factors have also influenced the establishment of this economic activity in this area in the past. There is evidence that rattan products have been produced in Sri Lanka since ancient times. The people who make rattan products are called "Kulu Pottan". Robert Knox also wrote about them in his travelogues (Jayawardena, 2015). Accordingly, it can be concluded that the rattan industry was still strong in the seventeenth century and may have received royal patronage. Village names such as Wewelduwa, Wewel Kandura, Wewelwala, Wewelpathana, and Weweldeniya indicate that the rattan industry has existed in Sri Lanka since ancient times (Jayawardena, 2015).

It is believed that the basic knowledge of rattan production came with the arrival of Sangamitta Theraniya. This evidence is further confirmed by the fact that among the 18 artisans who came to this country during the reign of King Pathis II was a group known as Kulu Potthan. Their task was to make various items using rattans. Native people of Sri Lanka also used rattans to make ladders for wasps (Liyanagedara, 2020). Different types of rattans are used when manufacturing rattan products. Some of them are Heen rattans, white rattans, ma rattans, kambotu rattans, Nara rattans, Malaysian rattans, Kekuna rattans and Ela rattans. However, well-ripped rattans are most preferred in manufacturing rattans rather than young rattans.

As in past in present also, rattan products are very popular among Sri Lankans as well as foreigners (Rathnayaka, 2019). Such products can sometimes be cited as one of the major reasons to attract foreigners to this country. In the past, rattan production in Sri Lanka was limited to the kitchen, but today the situation has changed. Nowadays, manufacturers are highly interested in making a variety of 
decorative products that can be placed in the living room and bedroom. The creation of various animal figures, various formats, wall hangings, lamp sets, etc, is practised in the present rattan manufacturing industry (Silva, 2019). However, currently, the people who are engaging in this industry are facing various challenges. Accordingly, various problems related to this industry can be identified.

The rattans, which have been manufactured based on local as well as foreign markets, are currently facing various challenges. The research goal of this paper is to do thorough investigations about, what are the current challenges associated with the rattan manufacturing industry in Sri Lanka?

\section{Methodology}

This research was carried out using a mixed methodology under the inductive approach. Quantitative and qualitative data were used for the research and they were collected from primary and secondary sources. The secondary data were collected through the DSD office, Resource profile, District statistical handbooks, Relevant websites, and journal articles. Moreover, the primary data was collected through questionnaires, structured and semi-structured interviews. Radawadunna Grama Niladhari Division of the Mirigama Divisional Secretariat Division in the Gampaha District was selected as the sample to conduct this study. The reason for selecting this area for this study was that this area is identified as a place significantly famous for rattan-related products and trade. Ten attributes were derived from the literature survey to identify the research objective. A factor analysis was performed using SPSS software and the analyzed data were presented in tables and charts. Map No. 01 below shows the location of the study area of this research in Radawadunna Grama Niladhari Division in Sri Lanka. 


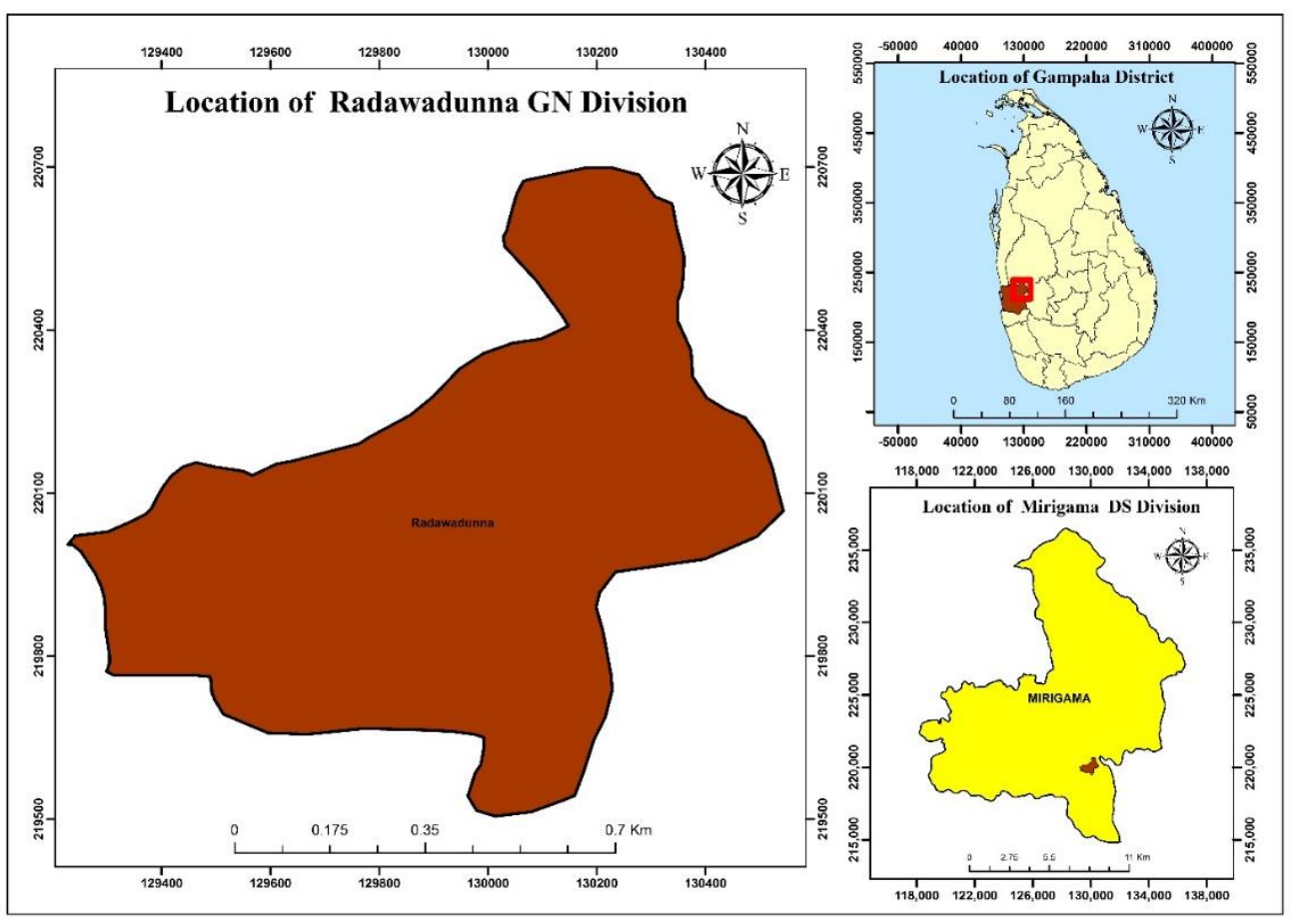

Map No. 01: Location of the Study area

Source - Using Arc GIS 10.1, 1:50,000 Digital data, Survey Department of Sri Lanka, (Rathnayaka, 2021)

\section{Research Discussion and Analysis}

\begin{tabular}{|l|c|}
\hline \multicolumn{1}{|c|}{ Variable } & Percentage \\
\hline Shortage of raw material & $16.8 \%$ \\
\hline Increase in production cost & $11.0 \%$ \\
\hline Increase in prices of manufactured goods & $10.3 \%$ \\
\hline The arrival of substitutes & $5.2 \%$ \\
\hline Decreasing the contribution of the current generation & $7.1 \%$ \\
\hline Increase in market tax rent & $5.2 \%$ \\
\hline Reducing profits & $7.7 \%$ \\
\hline Traditional industrialists are experienced due to aging Lack of staff & $7.7 \%$ \\
\hline Transporting raw materials costs a lot of money & $16.1 \%$ \\
\hline Culturally these producers are considered inferior to society & $12.9 \%$ \\
\hline
\end{tabular}

Table 1.1 indicates the percentage distribution of each attribute.

Table 1.1. Percentage distribution of the Initial Variables.

Source - Field Data, 2019 
According to table 1.1 , more than $15 \%$ indicated that shortage of raw material $(16.8 \%)$ and high transportation cost $(16.1 \%)$ as the burning issues respectively regarding rattan production. In addition to these variables, producers are considered inferior to society, high production costs, as well as high prices of manufactured goods, represented more than 10\%. Furthermore, arrivals of substitutes and increased market tax rent indicated around 5\%.

\section{Factor Analysis}

The significance of Bartlett's test (Table 1.2) confirmed that the observed correlation matrix is significantly different from the identity matrix. It also indicated that the KMO statistic $(0.826)$ is greater than 0.6 confirming that data satisfied sampling adequacy for FA. In addition to the KMO and Bartlett's test, it is recommended to compute Cronbach's Alpha Coefficient for categorical data (Peiris, 2018).

\begin{tabular}{lll}
\hline \multicolumn{2}{l}{ Kaiser-Meyer-Olkin (KMO) Measure of Sampling Adequacy } & .755 \\
\hline Bartlett's Test of Sphericity & Approx. Chi-Square & 121.555 \\
& Df & 21 \\
\hline & Sig. & 0.00 \\
\hline Cronbach's alpha coefficient & & 0.826 \\
\hline
\end{tabular}

Table 1. 2: Results of Adequacy Statistics for FA

The significance of the Bartlett Test $(\mathrm{p}=0.00)$ showed the correlation matrix is significantly different from the identity matrix. Cronbach's alpha coefficient of 0.826 confirmed that there is good internal consistency in data. All these results confirmed that the data set is suitable for FA. 


\section{Extraction Factors}

The number of factors to be retained was decided by the Kaiser's rule of which eigenvalues exceed unity. It was found that the four factors accounted for $87 \%$ of the variability of the original system. The factors were extracted using the PCF method and were rotated using Varimax.

The following table (Table 1.3) shows the factor rotation results under the Varimax rotation methods in the PCF method.

\begin{tabular}{|c|c|c|c|c|}
\hline \multirow[t]{2}{*}{ Reasons } & \multicolumn{4}{|c|}{$\begin{array}{l}\text { Componen } \\
\mathbf{t}\end{array}$} \\
\hline & 1 & 2 & 3 & 4 \\
\hline increase in production cost & .364 & .333 & .474 & .177 \\
\hline increase in prices of manufactured goods & .782 & .078 & $\begin{array}{c}- \\
.032\end{array}$ & .198 \\
\hline the arrival of substitutes & .859 & $\begin{array}{c}- \\
.023\end{array}$ & $\begin{array}{c}- \\
.098\end{array}$ & $\begin{array}{c}- \\
.041\end{array}$ \\
\hline Decreasing the contribution of the current generation & .745 & .176 & $\begin{array}{c}- \\
.077\end{array}$ & .136 \\
\hline Increase in market tax rent & $\begin{array}{c}- \\
.082 \\
\end{array}$ & .701 & .506 & $\begin{array}{c}- \\
.223\end{array}$ \\
\hline Reducing profits & .285 &. & $\begin{array}{c}- \\
.190\end{array}$ & .774 \\
\hline Traditional industrialists are experienced Lack of staff & .066 & .053 & .565 & .625 \\
\hline Transporting raw materials costs a lot of money & $\begin{array}{c}- \\
.158\end{array}$ & .185 & .834 & .104 \\
\hline Culturally these producers are considered inferior to society & $\begin{array}{c}- \\
.147\end{array}$ & .177 & .110 & .551 \\
\hline increase in production cost & .406 & .563 & .018 & .123 \\
\hline
\end{tabular}

Table 1.3: Factor Loadings of 4 - Factor Model (PCF and Varimax)

Based on the results in table 1.3, it can be confirmed that among the initial ten variables, increase in prices of manufactured goods, the arrival of substitutes, Decreasing the contribution of the current generation load more highly on the first common factor, increase in market tax rent and increase in production cost load 
more highly on the second common factor, increase in production cost, transporting raw materials costs a lot of money load more highly on the third common factor and reducing profits, traditional industrialists are experienced lack of staff, Culturally these producers are considered inferior to society load more highly on the forth common factor.

Thus, the four factors can be named as, resource scarcity, market factors, spatial factors, and cultural factors. Under these four main factors, several other sub-factors can be identified. Accordingly, the following are the challenges facing the rattan manufacturing industry today.

\section{Resource scarcity}

The main problem that has arisen in connection with this manufacturing industry is the scarcity of resources. It was identified a shortage of physical as well as human resources. There are two main challenges under resource scarcity. That is,

1. Shortage of raw materials

2. Scarcity of employees.

In the past, it was easy to get raw materials from this area, but today the situation has changed. As a result, those engaged in this industry have had to import raw materials from other areas. Raw material is currently being transported, especially from Ampara, Mahiyanganaya, Polonnaruwa and Trincomalee. Thus, manufacturers have to spend extra money to transport raw materials to the market from the abovementioned remote areas. Accordingly, the impact value of the raw material shortage was recorded as .474 . In addition to the shortage of raw materials, a shortage of human resources was identified as another challenge in the study area. There was a shortage of quantitative as well as qualitative human resources. The main challenge here is the lack of experienced workers due to the ageing of traditional industrialists. Accordingly, the scarcity of employees was .834. 
Since the rattan manufacturing industry is based on skills, it is very important to have more skilled labourers. Lack of skilled labor is also a current challenge associated with this industry.

\section{Market Challenges}

Market factors can be identified as another challenge with the rattan manufacturing industry. The primary challenges identified under market challenges were, an increase in production cost

1. Increase in prices of manufactured goods

2. The arrival of substitutes

Etc. were able to identify the challenges.

At the end of the study, it was found, several key factors contribute to increasing the cost of rattan products. Those factors are, such as the high cost of exporting rattan products, the need to pay various commissions on transportation, the high cost of labour due to the shortage of labour, and the increase in market rents. The value here was recorded as .782. Due to these factors, the cost of production of rattan products is very high and the shop owners have to increase the selling price of rattan products. Due to this situation, the number of local and foreign buyers is less than before. Another challenge is the availability of various substitutes for the rattan industry. With the introduction of substitutes made of plastic, aluminium, and fiber in the market and their prices being lower than rattan products, consumers are more motivated to buy those products.

\section{Local challenges}

Land is a more important factor in establishing primary economic activities. The following main challenges were identified locally with the rattan manufacturing industry, 
1. Increase in market tax rent

2. Reducing profits

3. High cost to transport raw materials

Some traders keep their shops under rent and the challenge they face is increasing the rent of the shop. In the past, these shops were in houses, but now they are rented out. As a result, traders from other areas continue their businesses for monthly rent in this area and they face this problem. Thus, the increase in market rent, the higher cost of transporting raw materials, and the increase in production costs affect reduce the production profits. This is also a challenge faced by traders associated with this industry.

\section{Cultural challenges}

Much of Sri Lanka's trade is still based on culture. The main factor here is to determine their social status based on the trades they make. Accordingly, cultural challenges can be pointed out as a challenge facing the rattan manufacturing industry today. Under cultural challenges, the following key challenges were recognized as existing challenges in present.

- Culturally these producers are considered inferior to society

- Decreasing the contribution of the current generation

The rattan makers in the society are called "Kulu Pottan". The importance of such individuals in the social hierarchy is still evident today. Due to this, the contribution of the modern generation to this industry has been minimal. Because of this low social concern. Accordingly, this can be identified as another challenge associated with the rattan manufacturing industry.

\section{Conclusion}

Primary economic activities are concentrated in different parts of the world and are caused by various physical and human activities. This research paper focused on identifying the current challenges faced by the rattan manufacturing industry in Sri 
Lanka. Accordingly, four major challenges related to the rattan industry and 10 other sub-challenges under them were identified. Major challenges identified in the Rattan manufacturing industry were resource challenges, market challenges, spatial challenges, and cultural challenges. As the resource challenges, the shortage of raw materials, and the shortage of trained and adequate human resources were identified in the study area. Under the market challenges, the increase in production cost, increase in prices of manufactured goods, the arrival of substitutes were identified. Local challenges identified in the study were, an increase in market tax rent, reducing profits, transporting raw materials costs a lot of money, and as cultural challenges, culturally these producers are considered inferior to society, decreasing the contribution of the current generation were identified. Thus, the study finally identified the main challenges associated with the rattan industry in present Sri Lanka.

\section{Reference}

Benton, A., Cronin, T., Frith, O., Jonkhart, J., \& Junqi, W. (2011). Market potential of bamboo and rattan products. Market Potential of Bamboo and Rattan Products. https://www.cabdirect.org/cabdirect/abstract/20123336557

Commercialization of forest products as a tool for sustainable development: Lessons from the Asian rattan sector - ProQuest. (n.d.). Retrieved September 3, 2021, from https://www.proquest.com/openview/73c467b30c3709f2c42f1e31548e71e4/1?pqorigsite $=$ gscholar $\&$ cbl $=18750 \&$ diss $=y$

Hindarsah, I., Purwanto, B., Priadana, S., \& Fahrudin, A. (2020). The Owner Factor: An Innovation Element of Business Model Canvas by SMEs Rattan Industry in Cirebon Indonesia. International Journal of Advanced Science and Technology, Vol. 29, No. 6, (2020), 3963-3972.

Huang, L., Chen, K., Zhou, M., \& Nuse, B. (2019). Gravity Models of China's Bamboo and Rattan Products Exports: Applications to Trade Potential Analysis. Forest Products Journal, 69(4), 337-344. https://doi.org/10.13073/FPJ-D-19-00022 
Liyanagedara, N. (2020, October 8). Lankawe Wewal Karmanthaya Gena Danagamu (Lets know about the cane industry in Sri Lanka). Retrieved from https://roar.media/sinhala/main/features/cane-industry-of-sri-lanka

Peiris, T.S.G. (2018). Handbook on Analysis of Multivariate Data using SPSS. Central Print Shop - Piliyandala. ISBN 978-955-90-2763-8.

Rathnayaka, R.M. Kalindu (2019). Current trends related to the trade in cane products: By Radawadunna Grama Niladhari Division (Wewal Nishpadana welandama Ashritha warthamana prawanatha: Radawadunna Gramasewa wasama Asurin), Conference Proceedings: 5th National Research Conference on Applied Social Statistics, Volume 02, December 2019.pp.9

Rathnayake, P. (2017, August 23). Wewaldeniya - Radawadunna Wewal Karmanthaya Anathure (Weweldeniya - Radawadunna cane industry in danger). Retrieved from http://www.lankadeepa.lk/provincial_news/

Silva, C. N. (2019). Adata Wada Hoda Wewal Karmanthaya (Better cane industry yesterday than today). Retrieved from http://www.deshaya.lk/article/51/ヶ๖రอઠ/13820 